\title{
Celebração do casamento igualitário e homofobia nas redes digitais: \#LoveWins na disputa de sentidos oriundos da apropriação da Havaianas ${ }^{1}$
}

\section{Ronaldo Cesar Henn, Jonas Pilz e Felipe Viero Kolinski Machado}

\begin{abstract}
Resumo
0 trabalho analisa os sentidos oriundos do modo como a marca de sandálias Havaianas apropria-se das manifestações em rede de apoio à decisão da Suprema Corte dos Estados Unidos, que tornou legal, em 2015, o casamento o igualitário naquele país. Ao atualizar sua foto de perfil no Facebook utilizando, inicialmente, o filtro com as cores do arco-íris e, depois, dispondo as sandálias em cores que lembram a bandeira do movimento LGBT, a marca desencadeou conversação em que sentidos em torno do tema homofobia foram se constituindo. A ação das Havaianas enquadra-se na condição de ciberacontecimento e articula intricadas relações, que passam por questões de gênero, narrativas espalhadas e permeabilidade de fronteiras mediáticas. 0 artigo também apresenta a experiência metodológica designada como Análise de Construção de Sentidos em Redes Digitais, que se ocupa de processos micros da conversação em rede.

\section{Palavras-Chave}

Ciberacontecimento. Disputa de sentidos.

Sites de redes sociais.
\end{abstract}

\section{Ronaldo Cesar Henn I henn.ronaldo@gmail.com}

Doutor em Comunicação e Semiótica pela PUCSP, Brasil. Prof. da PósGraduação em Ciências da Comunicação da UNISINOS, Brasil. Coordena o Laboratório de Investigação do Ciberacontecimento. Bolsista CNPq.

\section{Jonas Pilz | jonaspilz@gmail.com}

Bolsista CAPES no curso de Doutorado do Programa de Pós-Graduação em Comunicação da Universidade Federal Fluminense, UFF - Brasil. Mestre em Ciências da Comunicação pela UNISINOS, Brasil.

\section{Felipe Viero Kolinski Machado ।}

felipeviero@gmail.com

Pós-doutorando (PDJ/CNPq: 150038/2018-6) do Programa de Pós-Graduação em Comunicação Social da UFMG, professor substituto do curso de jornalismo da UFOP. Doutor em Ciências da Comunicação pela UNISINOS.

\section{Introdução}

0 termo ciberacontecimento designa uma proposta de conceito que visa a compreender a especificidade da produção de acontecimentos jornalísticos no âmbito dos sites de redes sociais (HENN, 2014). Pesquisas nessa perspectiva, desenvolvidas no Laboratório de Investigação do Ciberacontecimento (LIC - PPGCCOM/Unisinos), traçaram uma gama de casos que contemplam o conjunto de categorias identificadas nesses processos. São acontecimentos que envolvem desde mobilizações de cunho político, até os mais radicais entretenimentos. Pensados, inicialmente, em ambientes estritamente jornalísticos, os ciberacontecimentos também se engendram em espaços publicitários, potencializando suas lógicas. Entre os casos que foram mapeados nesse setor (PILZ, 2016), destaca-se o da marca de sandálias Havaianas, que se vinculou de forma distinta a uma proliferação de manifestações em rede por conta da decisão da Suprema Corte dos Estados Unidos, que tornou legal, naquele país, o casamento igualitário. 
A homofobia constitui-se como um preconceito de grande monta na história da humanidade (FONE, 2008; BORRILL0, 2010) e ganha uma discussão intensa na sociedade contemporânea, exatamente pela visibilidade que conquista na disputa de sentidos que se orquestram em redes digitais. Nesse cenário, este artigo visa a analisar esse caso específico, para que se extraiam deles inferências que possam ajudar a compreender as tensões postas nesse conjunto de agentes. Entende-se que o caso da marca Havaianas, aqui pautado, articula, nos seus meandros, intricadas relações que falam do acontecer contemporâneo: construções de identidades múltiplas vinculadas à perfomatividades em rede - as quais também atravessam-se em construções de gênero; narrativas espalhadas, no sentido conferido por Jenkins, Ford e Green (2013); intensa permeabilidade de fronteiras nas delimitações mediáticas tradicionais - com implicações especiais no sistema jornalístico, e potencialização de tensões semiosféricas na busca por hegemonia de sentidos.

Na sua primeira parte, 0 artigo contextualiza as discussões em torno de homofobia e construções de gênero. Na segunda, atualiza-se o conceito de ciberacontecimento e seus desdobramentos na cultura mediática contemporânea, entre eles, os que se processam nas relações entre a produção de acontecimentos jornalísticos em rede nas interfaces com a publicidade. Na terceira, descreve-se 0 caso com a análise das suas articulações a partir da identificação dos sentidos em construção. E, no final, estabelecem-se as considerações finais com a sistematização das inferências obtidas.

\section{Homofobia e gêneros}

Byrne Fone (2008), ao traçar uma história da homofobia, destaca que, através do tempo, as pessoas têm encontrado suficientes causas para desconfiar, depreciar, atacar e, em ocasiões especiais, matar sem piedade seus vizinhos por diferenças de religião, nacionalidade e cor. 0 autor entende que, de fato, são poucos os grupos sociais que estão livres de alguma forma de preconceito, porém a maioria dos segmentos opostos entre si - homens e mulheres; judeus, muçulmanos e cristãos; negros e brancos - estariam unidos por um ódio classificado como eterno: a aversão por um determinado grupo cuja presença é universal. "Os preceitos religiosos condenam este grupo; as leis da maioria das nações ocidentais os têm punido. São poucas as pessoas que se importam em admitir sua presença entre eles" (FONE, 2008: p. 17). Trata-se do grupo formado pelos conjuntos de pessoas designadas como homossexuais. "A antipatia em relação a eles - e a condenação, aversão, temor e banimento da 
conduta homossexual - é o que se denomina como homofobia" (FONE, 2008: p. 17).

Elisabeth Young-Bruehl (1996), em The anatomy of prejudice, ao abordar os principais preconceitos em voga estabelece outra combinação de categorias: obsessivos, histéricos e narcisistas. 0 preconceito obsessivo considera seus objetos de fúria como conspiradores onipresentes, ou inimigos que se empenham em destruí-lo. Por conta disso, precisam ser eliminados. 0 preconceito histérico - que tem um forte componente de repressão sexual - interpreta os indivíduos odiados como "outros", "inferiores", ou uma "ameaça sexual". 0 preconceito narcisista constrói-se na impossível tolerância da existência de pessoas que não sejam como si mesmas.

A homofobia estaria entre os preconceitos que concentram, em graus diferentes, as três categorias identificadas.

Daniel Borrillo (2010) compreende a homofobia como uma manifestação arbitrária que consiste em designar o outro como contrário, inferior ou anormal. Destaca algumas expressões que constituíram a homofobia ao longo da história, entre elas: crime abominável, amor vergonhoso, gosto depravado, costume infame, paixão ignominiosa, pecado contra a natureza, entre outras. Mesmo que seja aceita na esfera íntima da vida privada, "a homossexualidade torna-se insuportável ao reivindicar, publicamente, sua equivalência à heterossexualidade" (BORILLO, 2010: p. 17). Nesse sentido, 0 autor conceitua a homofobia, também, como o medo de que a valorização dessa identidade seja reconhecida, na perspectiva de que ela possa destituir a fronteira e a hierarquia da ordem heterossexual. A homofobia, nesse sentido, representa o risco de desestabilização que a homossexualidade pode gerar, perturbando convenções sociais, políticas e econômicas, bem como as performances de gênero esperadas de homens e de mulheres (FONE, 2008).

Ao incitarem 0 debate teórico sobre gêneros e sexualidades, uma série de trabalhos, que depois viriam a ser percebidos como queer, promovem, dentre outras coisas, uma desconstrução radical de qualquer discursividade homofóbica. Produzidos a partir de um lugar de fala marginal, escritos em grande parte por gays e lésbicas envolvidos em movimentos ativistas e, também, acadêmicos, os estudos queer, ao tomarem a palavra para si, propõem que se reflita sobre 0 lugar dos subalternos pelo ponto de vista deles próprios. Ao deslocarem a injúria (uma vez que o próprio termo queer, em inglês, referir-se-ia ao um xingamento, significando algo como estranho ou esquisito) e ao erguerem-se sobre ela para falar, tal perspectiva propicia um questionamento radical dos processos de subjetivação (PRECIAD0, 2009).

No que se refere ao contexto de seu desenvolvimento, pode-se dizer que as origens do que se concebe como teoria queer estariam ligadas à segunda onda feminista, ao movimento negro do

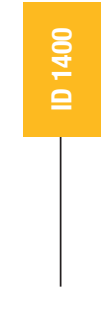


sul dos Estados Unidos e, mais especificamente, à postura da população em geral frente aos homossexuais, que - em um cenário de epidemia de AIDS e pelo medo da contaminação - eram percebidos como grupo abjeto, cuja repulsa era recomendada e estimulada (queer nation). De um ponto de vista teórico e metodológico, ainda, ela seria herdeira do encontro dos Estudos Culturais norte-americanos com o Pós-Estruturalismo francês, tendo como aspecto importante a desconstrução das noções clássicas de sujeito e de identidade (MISKOLCI, 2007;2012).

Tomada como perspectiva teórica e política, a teoria queer consolida-se ao estabelecer sua crítica tendo em vista um modelo de hegemonia heteronormativa e os binarismos (hetero/ homo; homem/mulher; integrado/excluído) que o chancelam. Conforme lembra Córdoba (2005), ao considerar a sexualidade como um campo aberto de relações de poder e como uma dispersão de pontos de dominação e de resistência, a teoria queer propõe que a resistência se dê em múltiplos espaços articulados e políticos. Tal qual diz Preciado (2009), trata-se de um espaço de empoderamento e de mobilização revolucionária.

Judith Butler (2012), uma das principais autoras desse campo, introduziu importante ruptura quando propôs que não apenas o gênero engendra-se como construção, mas o próprio sexo: a ideia de um sexo pré-discursivo apenas asseguraria a estabilidade de uma lógica binária e a manutenção de dicotomias (macho/fêmea).
Longe de serem substâncias permanentes, portanto, as categorias sexo e gênero teriam a sua coerência e relação estabelecida a fim de garantir a manutenção daquilo que Rich (2010) definiu como "heterossexualidade compulsória".

Resulta daí que 0 gênero não está para a cultura como 0 sexo está para a natureza; ele também é 0 meio discursivo/cultural pelo qual a natureza sexuada ou um sexo natural é produzido e estabelecido como pré-discursivo. (BUTLER, 2012, p. 25)

Dessa forma, toma o gênero como "uma complexidade cuja totalidade é permanentemente protelada" (BUTLER, 2012, p. 37). A autora questiona a razão desse binarismo recorrente (masculino/feminino) e traz a noção de "gêneros inteligíveis" a fim de discorrer sobre aquilo que, mantendo a continuidade esperada entre sexo/gênero/desejo, seria aceito, bem como sobre aquilo que, rompendo com esse velho sonho simétrico, seria incompreensível e, por conseguinte, posto à margem (HENN e MACHAD0, 2015).

Tomando, então, o gênero como um contínuo fazer, como um devir e uma atividade, e aproximando-se da noção de performance de Austin (1962), Butler (2012, p. 48) dirá que ele se mostra "performativo no interior do discurso herdado da metafísica da substância - isto é, constituinte da identidade que supostamente é", consistindo em uma repetição que se dá no corpo, dentro de um quadro regulado e controlado, e que, ao longo do tempo, adquiriria a aparência de uma naturalidade. 


\section{Ciberacontecimentos}

Entre as teorias do acontecimento, destaca-se formulação proposta por Louis Quéré (2005), que o situa no nível da afetação e da experiência. Em outras palavras, 0 acontecimento só atinge essa estatura quando vivido no campo da experiência: ele afeta sujeitos que, a partir da sua vivência, necessitam dar sentido à sua emergência. Ao produzir sentidos e experiências, 0 acontecimento instala campos problemáticos em torno dos quais comunidades inteiras podem se articular em potenciais disputas de sentidos. 0 jornalismo, desde a sua consolidação nas sociedades liberais e industriais do século XIX, transformou-se em instituição pública (ao mesmo tempo de natureza privada e comercial) que trouxe para si a hegemonia tanto das narrativas sobre os acontecimentos, como da pauta do debate público que eles suscitam.

Esse protagonismo do jornalismo como mediação privilegiada entre acontecimentos públicos e sociedade atravessou o século XX e desencadeou propostas teóricas importantes, como as teorias construcionistas (TUCHMAN, 1983; ALSINA, 1989; TRAQUINA, 2004), agendasetting (McCOMBS, 2009) e das que se dedicam especificamente ao acontecimento jornalístico (BERGER e TAVARES, 2010).

Com 0 avanço das plataformas digitais e conexões online, o jornalismo inicia processo de transformação de suas práticas, seus formatos e narrativas (PALÁCIOS e NOCI, 2009; MACHADO e PALÁCIOS, 2003; MIELNICZUK, 2004; SCHWINGEL, 2012 ). A partir dos ambientes possibilitados pela web 2.0, no começo dos anos 2000, potencialidades como interatividade, hipertextualidade, multimidialidade, personalização, instantaneidade e memória são absorvidos pelo jornalismo, o que não só altera os modos de circulação dos seus conteúdos, como também estabelece novas formas de relação com seus públicos, que passam a ter papel mais ativo nessas construções. Em paralelo, experiências autônomas advindas da configuração dos blogs e da blogosfera (PRIMO, 2007; RECUERO, 2003) fazem aparecer narrativas sobre acontecimentos que escapam dos núcleos hegemônicos do jornalismo tradicional.

A consolidação dos sites de redes sociais e dos smartphones, associadas às tecnologias $3 \mathrm{G} \mathrm{e}$ 4G, intensificam as dinâmicas de conectividade e aprofundam as transformações em curso. 0s ambientes de convergência, que impulsionaram alterações profundas no plano da cultura (JENKINS, 2009), desdobram-se em processos de espalhamento mediático. Migra-se, de vez, de processos distributivos, concentrados no topo das organizações de mídia, para processos de circulação, de características híbridas e não lineares (JENKINS, FORD e GREEN, 2013). 0 conteúdo literalmente espalha-se numa série de transações entre agentes de diferentes quilates. Configura-se, nessa cena tecnológica e cultural, o jornalismo em rede (HEINRICH, 
2011; RUSSELL, 2011), em que as narrativas convertem-se em nós conectivos agenciados por plataformas e atores distintos.

Esse conjunto de condições sistêmicas iniciais (HENN e OLIVEIRA, 2015) faz eclodir o que se designa aqui como ciberacontecimentos (HENN: 2014). Trata-se de acontecimentos que, na condição de expressões contemporâneas da cibercultura, constituem-se em redes digitais e geram narrativas de natureza convergente e transmidiática: sua potência vinculase ao nível de afetação que propulsiona, intensificada pela experiência desse acontecer em rede. Mobilizações globais, ações digitais, exercícios de cidadania, ações afirmativas, entretenimentos e subjetividades compõem categorias provisórias de ciberacontecimento, delineadas pelas pesquisas que se dedicam a investigá-lo (HENN, 2015).

Os ciberacontecimentos, nos modos como se compreendem nesse texto, apresentam, pelo menos, três dimensões a serem consideradas: os processos transnarrativos e hipermidiáticos que incluem a presença de outros atores fora dos núcleos do jornalismo tradicional; a reverberação instantânea que passa a ser incorporada na própria narrativa, também a constituindo; e a eclosão desses outros modos de acontecimento que se tramam no cenário de conexões sistêmicas altamente complexas (HENN, 2013). Essas dinâmicas potencializam uma crise no jornalismo contemporâneo, de natureza sistêmica, que afeta parâmetros como o da estruturalidade e da identidade (HENN e OLIVEIRA, 2015).

Entre os atores que se vinculam a essas novas formas de acontecer, estão os oriundos do campo da publicidade. Percebe-se a emergência de casos em que se identificam estratégias de visibilidade e inserção de marcas, tanto nas interfaces dessas narrativas, como também na incorporação de suas dinâmicas. Esse comportamento do mercado publicitário problematiza as fronteiras sempre delicadas com o jornalismo. Na sua modalidade impressa, no século XIX, o jornal compunha um meio no qual a publicidade vinculava-se, tanto do ponto de vista da sustentabilidade de um modelo de negócios, como - no plano semiótico -, no estabelecimento dessas fronteiras. Em cenário convergente e de espalhamento mediático, essas fronteiras tornam-se fortemente porosas.

0 vínculo com acontecimentos também é uma forma de perfomatizações contemporâneas, que envolvem capitais sociais (RECUERO e ZAG0, 2011) e construções de identidades (HENN, GONZATTI e MACHADO, 2016). São performatizações de si, que implicam a construção de narrativas, em que se percebem a permeabilidade de códigos, entre outros, do jornalismo, da moda, da cultura pop e da publicidade. Campos problemáticos desenham-se em disputas, muitas vezes, acirradas de sentidos, dando nova mobilidade à semiosfera (no sentido de LOTMAN, 1999). As questões de gênero estão entre as fontes que irrigam a rede nessas tensões 
semiosféricas. 0 caso da marca Havaianas, que passamos a descrever e analisar, contém elementos importantes na problematização do ciberacontecimento.

\section{Troca de imagens de perfil em apoio ao casamento civil igualitário}

A aprovação do casamento igualitário pela

Suprema Corte dos Estados Unidos, em

26/06/2015, teve grande impacto no mundo.

Embora alguns Estados já houvessem aprovado

leis de igualdade nesse sentido, a Suprema

Corte daquele país tornou o direito ao casamento

civil uma lei federal, válida em todo o território

estadunidense. Após o anúncio da aprovação,

muitos atores sociais, entre eles personalidades

e instituições, manifestaram-se a respeito

e assumiram posicionamento. 0 Facebook

disponibilizou um aplicativo para que os seus

usuários modificassem a imagem de seus perfis,

aplicando um filtro com a bandeira do arco-íris, que

é utilizada como símbolo pelo movimento LGBT.

Além disso, atores sociais em rede passaram

a produzir e reproduzir mensagens de apoio à resolução norte-americana com a utilização das hashtags "\#LoveWins" e "\#Loveislove", que evidenciam 0 valor emocional da afetação da decisão jurídica. Assim, a hashtag é entendida como dotada de um sentido de positividade, uma vitória que, mesmo atendendo a demandas específicas, tem um sentido universal e pode ser comemorada por todos aqueles que, agora, partilham dos mesmos direitos em relação à união civil.

Após a decisão da Suprema Corte, a circulação da notícia nos veículos de comunicação e as mobilizações de apoio e de contrariedade nos sites de redes sociais, tanto instituições públicas, como as com interesses mercadológicos, passaram a demonstrar seu posicionamento em torno do acontecimento, aplicando o filtro nos avatares, ou outro tipo de ícone das marcas, ou ainda desenvolvendo suas próprias publicações a respeito. A mobilização foi percebida primeiramente nos Estados Unidos, e depois em outros países, como o Brasil.

Em sua página no Facebook, a Havaianas fez duas atualizações relacionadas ao caso (Figura 1). A primeira atualização foi uma nova "foto de perfil" da página, no período vespertino, contendo a imagem de parte de um chinelo da marca com a bandeira do arco-íris, e nenhum texto complementar. A segunda atualização é uma publicação que foi realizada no período noturno, e apresenta a foto de chinelos da marca dispostos em colunas, que replicavam algumas das cores da bandeira do arco-íris. Mesmo sem conter todas as cores da bandeira no seu conjunto, a hashtag \#LoveWins, utilizada na legenda como texto único, não deixa dúvidas. A utilização também contempla a participação da Havaianas nos dois principais recursos de circulação e posicionamento do ciberacontecimento: a legenda e 0 filtro. 
Figura 1: Atualizações da página Havaianas
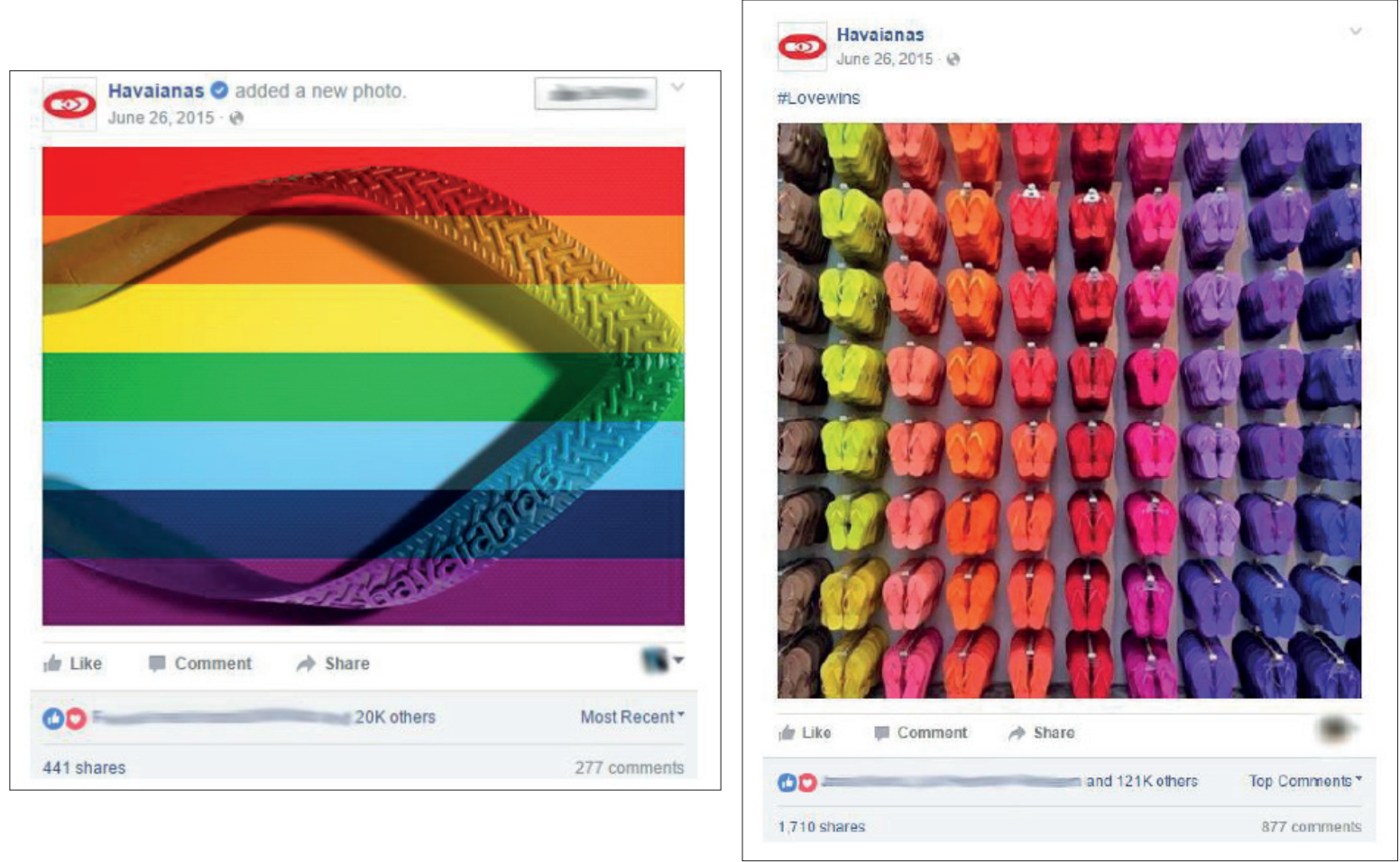

Fonte: Facebook

0s sentidos oriundos da conversação em rede originada pela Havaianas são observados apenas a partir dos comentários publicados nos espaços disponibilizados pela página da marca. A metodologia utilizada neste trabalho é a Análise de Construção de Sentidos em Redes Digitais, em desenvolvimento no Laboratório de Investigação do Ciberacontecimento - LIC. A metodologia em curso difere da Análise de Redes Sociais (FRAGOSO, RECUERO E AMARAL, 2011), de significativa contribuição ao campo de conhecimento em tela, que se caracteriza por uma natureza macro. No caso desta pesquisa, aquilo que se quer encontra-se nos interstícios das postagens, a partir de uma escala micro.
Pode-se pensar as abordagens em questão em, pelo menos, duas escalas de sentido. A que se constitui de forma macro, através de conexões e linhas produzidos pelos atores sociais envolvidos, e a que se dá no plano micro, constituída pelas constituintes de conexões, através das quais os atores sociais desencadeiam semioses específicas. E é nesse plano que a Análise de Construção de Sentidos em Redes Sociais passa a atuar.

De inspiração cartográfica (no sentido de Rolnik, 1989), e com técnicas que se aproximam da Análise do Conteúdo (BIRDAN, 1977), a metodologia ancora-se no conceito de semiose, de C. S. Peirce (2002), que permite compreender a ação dos signos 
e a própria constituição de sentidos, a partir de dinâmicas auto-organizacinais de geração de interpretantes. Nas conversações/conexões em rede e suas interfaces, há dinâmicas intraprocessuais de geração e apropriação de sentidos em que DNAs semióticos instituem-se e transmutam-se. Nucleações de sentido vão se desenhando, gerando cartografia que se dá na interface entre fronteiras, do que é interior e é exterior.

A metodologia opera-se a partir de três etapas principais, a) mapeamento e coleta; b) identificação das nucleações de sentidos e categorização; e c) inferências dos sentidos oriundos das conversações dos ciberacontecimento. 0 primeiro passo inicia-se a partir da percepção de um ciberacontecimento e do acompanhamento da conversação que gera. Ainda na primeira etapa, os desdobramentos das conversações surgem como indícios e elementos verificáveis. 0s sentidos dão-se por proximidade ou divergência: sua percepção e identificação pedem observação recorrente em volumes mais extensos de posts. Isso exige formas de coletas que contemplem a totalidade das mensagens postadas no âmbito das amostras definidas e dos seus comentários.

0 processo de categorização tem uma natureza subjetiva, uma vez que é constituído pelas percepções do pesquisador a partir de discursos de outrem. Contudo, a técnica de aproximação desses discursos, através dos elementos perceptíveis (como 0 assunto de que se trata, as formas de argumentação, o posicionamento político-social implícito ou explícito e, sobretudo, a performatização em que se institui) contribui para controlar as subjetividades em jogo. Nesta etapa, é comum o surgimento de ideias de categorias iniciais, em número expressivo, antes de serem confrontadas em trabalho minucioso de categorização.

Na segunda etapa - de identificação dos núcleos de sentido e categorização, com a visualização dos comentários -, as categorias são organizadas a partir da aproximação das categorias iniciais. Os sentidos, pensados a partir do conceito de semiose (PEIRCE, 2002), são desdobramentos de uma produção configurada a partir de interpretações atribuídas a objetos e fenômenos, através da mediação de uma rede interpretante. Como signos, os sentidos sempre se referem a uma outra coisa, ainda que possam representá-la com grande fidelidade ou com grande distância. Pelo seu dinamismo, mesmo os sentidos amplamente compartilhados por atores sociais podem não ser partilhados pelas mentes de determinadas pessoas. Sobretudo em uma sociedade em rede, a produção de sentidos, em um processo potencialmente infinito, pode gerar sentidos múltiplos e contrastantes.

Essas características de não consensualidade dinâmica, compartilhamento e a própria complexidade dos fenômenos e das mentes das pessoas possibilitam que se visualize a construção de sentidos em redes digitais como interseções entre as categorias formada por esses sentidos. Na fase de categorização, embora ainda exista um número significativo de categorias, oriundo 
da etapa de mapeamento, a contemplação das mensagens e das categorias inicialmente propostas permite que se percebam as suas proximidades. Esse processo torna as etapas indissociáveis. A terceira, a de inferências, abrange os demais processos desenvolvidos até então em torno do objeto, do referencial teórico e dos desdobramentos em torno do caso, a serem discutidos, e que determinarão as considerações em torno das questões de pesquisa. As categorias, do modo como são pensadas nessa proposta, não são rígidas, nem definitivas: comportam-se como constelações de sentidos suscetíveis a diversas flutuações.

Neste caso, o processo desdobrou-se em três etapas: 1) mapeamento e identificação, 2) categorização e 3) inferências. Após a identificação do ciberacontecimento e da apropriação da página da Havaianas, observam-se os comentários nas atualizações, com a intenção de perceberem-se os desdobramentos da conversação em torno do acontecimento e outras possíveis referencialidades. Aqui, já podem ser definidos, de forma abrangente, alguns sentidos, embora ainda não organizados em categorias. Na etapa de categorização, delimitaram-se os núcleos de sentidos. Tratando-se de processos em redes, as categorias propostas não são fechadas: são porosas e cambiantes, mas com traços suficientemente comuns para endossar a produção de inferências.

Propõe-se também a representação dos sentidos através de esferas de sentido e sentidos específicos, na etapa de categorização. As esferas de sentido são as referências das mensagens, os destinatários dos comentários, a que ou quem são direcionadas. Os sentidos específicos são as atribuições de sentido propriamente dadas nessas mensagens. Esta proposta surge a partir do reconhecimento de que, em conversações em rede, as mensagens carregam não apenas sentidos, mas seus endereçamentos, mesmo que não se trate especificamente de pessoas. As esferas de sentido, contudo, já estão carregadas de significação e contribuem para a demonstração das interseções entre as categorias.

Dentro dessa proposta, são identificadas três esferas: a) Havaianas, que agrega as mensagens direcionadas à empresa, a seus produtos e às apropriações do acontecimento; b) Resolução e desdobramentos, esfera que corresponde aos comentários sobre a decisão da Suprema Corte, a repercussão e as especificidades da celebração nas redes digitais, como a \#LoveWins e o filtro do Facebook; c) Crenças religiosas, referente aos comentários fundamentados em textos religiosos e a interpretação deles.

Quanto aos sentidos específicos, identificaramse nove:

\section{Reconhecimento e implicações do} posicionamento: este núcleo abrange as mensagens que entendem as atualizações da Havaianas como um posicionamento perante 0 acontecimento, atitude que a transforma em 
uma organização vinculada à causa LGBT, cujo público-alvo passaria a ser composto por pessoas que apoiam o casamento igualitário. Há a sugestão de que, quem não apoia deveria ter predileção por outras marcas, refutando a Havaianas e impactando sua receita.

Orgulho da marca: manifestações de apoio à Havaianas e ao seu posicionamento, que demonstram afetos anteriores, marcados por relações comerciais ou trabalhistas que sugerem pertencimento.

\section{Associação a outras campanhas e}

posicionamentos de marcas: este núcleo agrega as mensagens em que há a associação da apropriação da Havaianas com outras campanhas publicitárias recentes envolvendo o tema LGBT. Destaca-se, sobretudo, a campanha de 0 Boticiário para 0 "Dia dos Namorados" de 2015. Sentidos de acontecimentos próximos entrecruzam-se aqui.

Figura 2: Reconhecimento e implicações do posicionamento

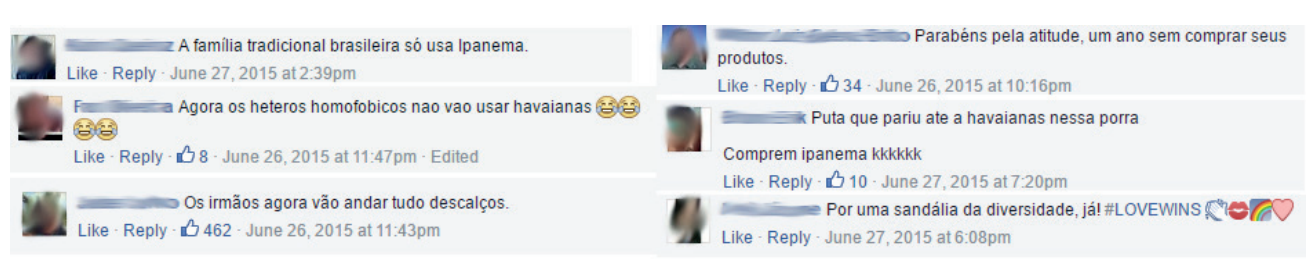

Fonte: Facebook

Figura 3: Orgulho da marca

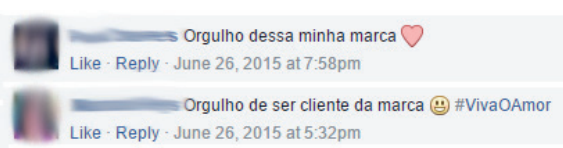

Like - Reply - June 26, 2015 at 5:32pm

Fonte: Facebook

Figura 4: Associação a outras campanhas

A Johnson tirou um comercial do ar pelo nosso protesto, como também a Red Bull, a Boticário, a Natura... todas tiveram quedas na receita. É um questão de tempo...

Like - Reply - 37 - June 26, 2015 at 10:34pm 
Deslegitimimação (e legitimidade) $d a$ mobilização perante outros problemas: nesta categoria estão mensagens que questionam a repercussão e a mobilização em torno da aprovação do casamento igualitário, entendido como uma "causa menor" ou até mesmo como uma "não causa", enquanto outras causas, como a fome e a miséria, por exemplo, seriam deixadas de lado pela atenção das pessoas. Ela também agrega as mensagens que contestam esse sentido. 0 que confere legitimidade é nomeado em segunda posição na categorização, porque surge como resposta às atribuições de deslegitimação.

Figura 5: Deslegitimação

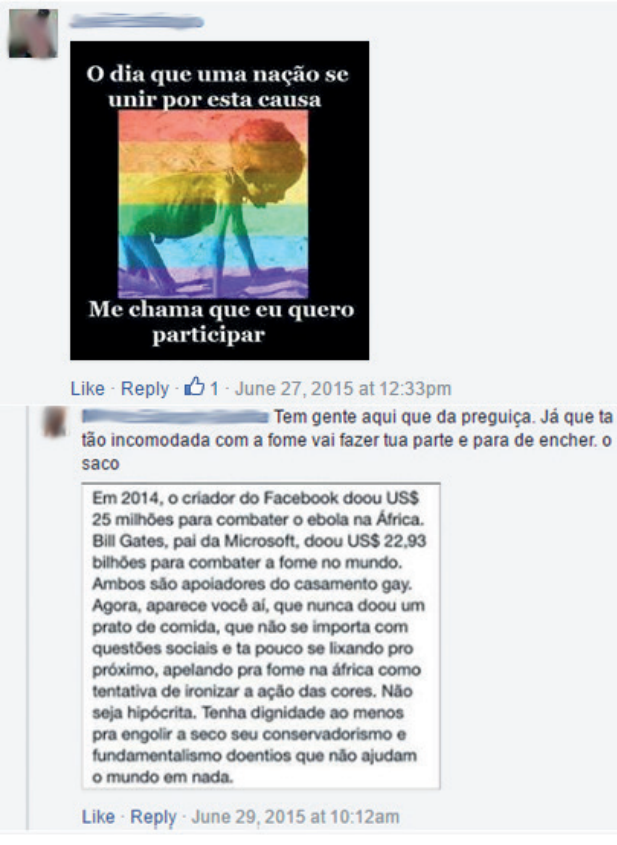

= Grande bosta lutar contra a fome ninguém quer, mais fica com essa palhaçada de ficar ajudando um bando de desocupado e fácil que envergonhado mundo eles querem Deus volta logo pra limpar o mundo dessa imundicie

Like - Reply - B 1 - June 27, 2015 at 3:11 pm

Pa n fazem havaianas contra a fome, destinando uma parte (

Sifizerem uma dessas eu compro concer

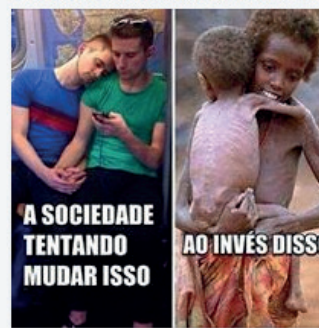

Like - Reply - June 27,2015 at 6.25pm

num Por um acaso vc apoia a campanha do agasalho, campanha contra a fome??? Me poupe

$$
\text { Like - Reply - B 7 - June 27.2015 at 6:35om }
$$

O povo fica ai flando q 0 gue precisa é campanha contra a fome os caraio, mas não tira um real do bolso p doar pra

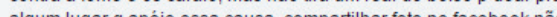
gu mata fome não meus amores. Eu apenas to dizendo q defendo sim aqueles q merecem, e quem não ta gostando posso fazer nada. Opinião é igual cu cada um tem o seu e faz dele oque quiser.

Fonte: Facebook

\section{Dissociação entre heterossexualidade e}

preconceito: esta categoria surge a partir

do entendimento de que alguns discursos

contrários ao casamento igualitário e/

ou homofóbicos poderiam atribuir a

heterossexualidade como condição determinante na configuração desses

posicionamentos. Nestas mensagens, os

atores sociais afirmam serem heteroessexuais

e apoiadores da decisão da Suprema Corte, das lutas LGBT e contra os preconceitos sofridos por estes. 


\section{Figura 6: Dissociação}

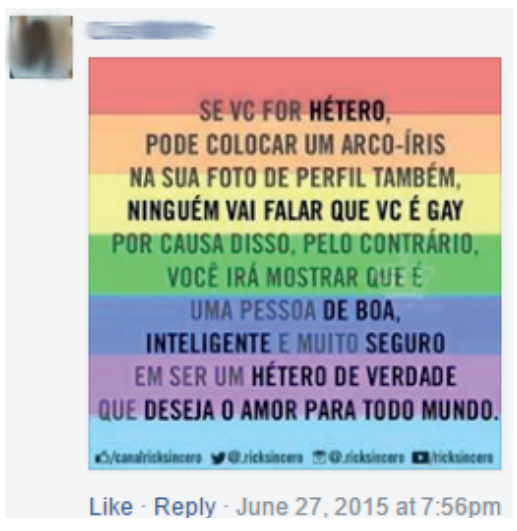

Não sou lésbica e mesmo assim luto contra a homofobia.. Deus fez a mulher e o homem ok.. e dai? ! Qts casais heteros estão nesse exato momento brigando, traindo ou até mesmo abandonando seus filhos, e um casal "gay" está feliz por poder se amar e melhor ainda cuidar do filho que 2 diferentes fez questão de abandonar. . Chora que o choro é livre. Like - Reply - 8 - June 27,2015 at 12:37am - Edited

N Não preciso ser gay para lutar contra a homofobia.! ६? Like - Reply - 1 1 - June 26,2015 at 9:01pm

Sou hetero ,mais apoio cada um de nós tem o livre arbítrio podemos escolher o que queremos ser ... \#OMundoPrecisaDeMaisAmor Like - Reply - June 27, 2015 at 2:32pm

Fonte: Facebook

\section{Figura 7: Preconceitos}

S \#APOIO' ant gente infantil, um Zé Povinho \#PRECONCEITUOSOS, a realidade é estampada doa em quem doer \#EUQUERO \#HAVAIANASDIVERSIDADE

Luincontinto Ridículo é o preconceito de vocês idiotas aceitem todo mundo tem direito de amar quem bem intender. Vão amar tbm que isso que tá faltando na vida de vcs $@ Q Q$

Like - Reply - June 27, 2015 at 2:47pm
Não sei oq esse povo pensa realmente. Querem que todo mundo ache tudo bonito e concordem com tudo o q eles querem. E se um não concordar acham que é preconceito, homofobia e mimimi..

Like - Reply - 30 - June 26, 2015 at 11:35pm

Dian não tenho preconceito cada um faz da entende, apenas deu minha opinião como gays na como disse alguns ultrapassam os limites e ra o preconceito.

Like - Reply - June 27,2015 at 11:57am - Edited

Fonte: Facebook

Preconceitos: nesta categoria estão

mensagens que atribuem sentidos

de preconceito e falta de respeito

aos discursos contrários e de apoio

ao acontecimento, à publicação e à

Havaianas. Há também mensagens que

relativizam a atribuição de preconceito nas

manifestações opinativas. 0 preconceito

aqui é sempre direcionado para "o outro".
Relativização da homofobia: esta categoria

emerge da observação de mensagens que se

associam a argumentos de relativização de causas

minoritárias, na contestação de que atualmente,

"qualquer coisa" seja considerada homofobia.

Esse núcleo pauta-se pela defesa de que discursos

contrários ao casamento igualitário deveriam

ser tratados apenas como opiniões que estariam

asseguradas pelo princípio liberdade de expressão. 


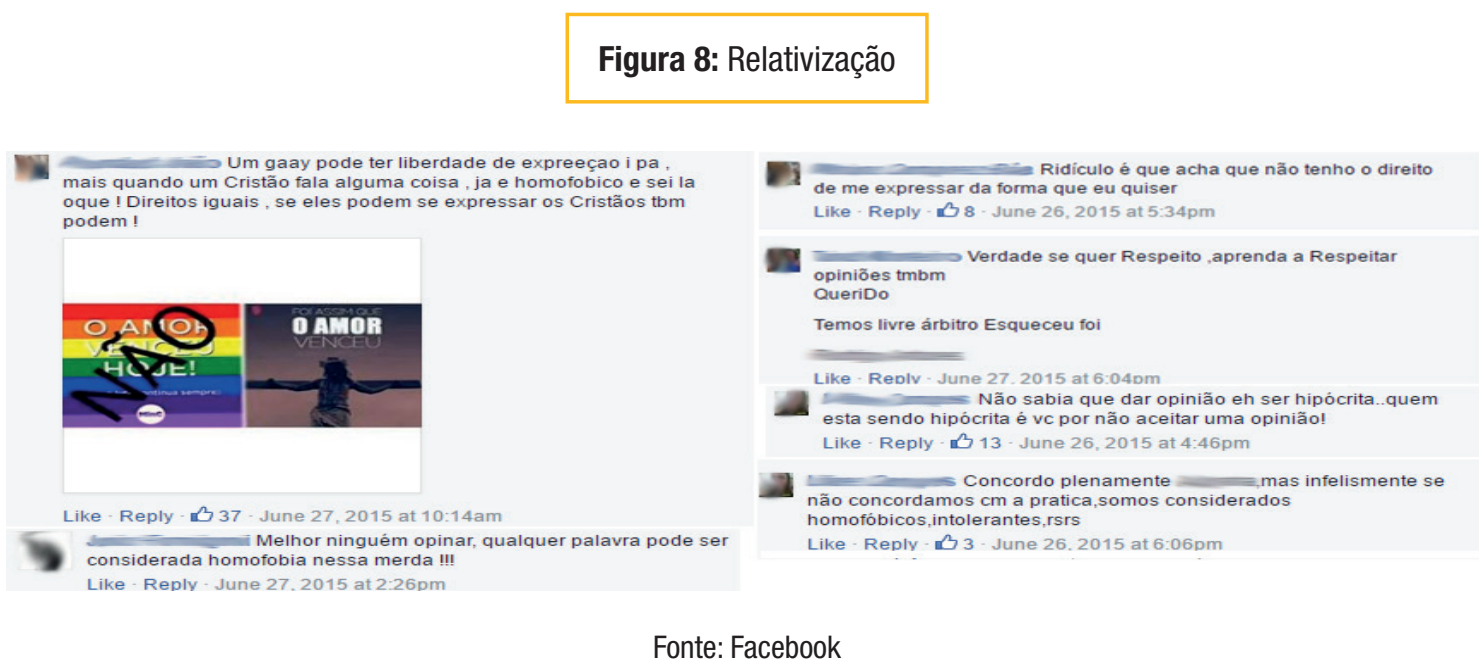

Orientações apocalípticas e ironização: nesta Discursos de conciliação: esta categoria surge categoria encontra-se a produção de sentidos oriundas de interpretações dos textos bíblicos e crenças cristãs, com ênfase no castigo severo para quem não segue esses dogmas, exaltado pelo "juízo final" ou "a volta de Jesus Cristo". Esta categoria também é entendida de forma bilateral, já que as mensagens são contrastadas com uma ironização do sentido aplicado. a partir da percepção dos atores sociais de que há um embate já configurado entre favoráveis e contrários ao casamento igualitário, à legitimidade da homossexualidade e ao posicionamento da Havaianas. As mensagens têm caráter de conciliação, de "cessar-fogo" entre xingamentos e disputas, apontando que opiniões devem ser respeitadas, assim como as escolhas e vidas individuais não devem ser julgadas pela falta de consonância com determinadas crenças e opiniões.

\section{Figura 9: Orientações apocalípticas}
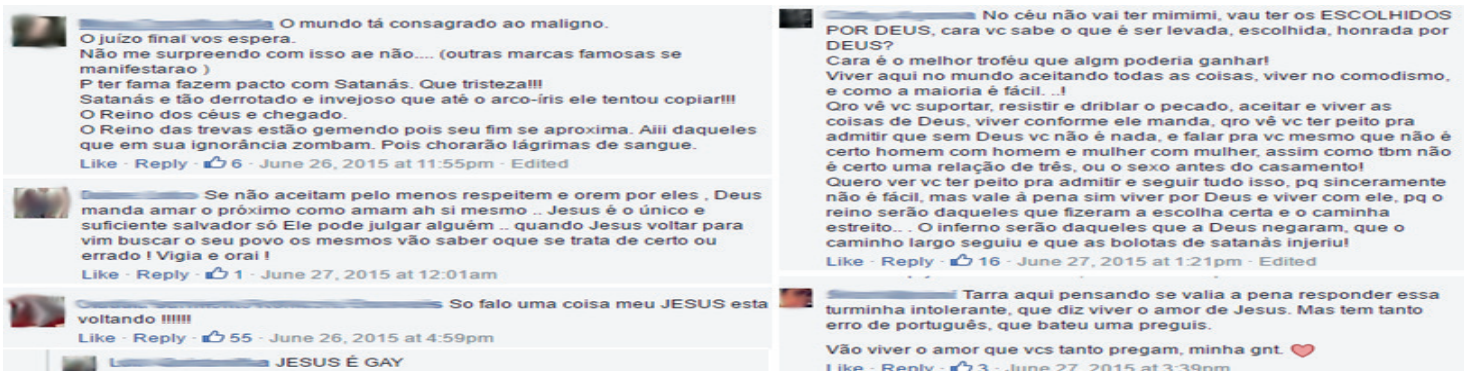
Figura 10: Discursos de conciliação

Amaras o senhor teu

Deus sobre todas as coisas e ao teu próximo como a ti mesmo.

Meus queridos jovens, parem de se agredir e se torturarem com ofensas. Deus deu a cada um de nós o livre arbítrio. Somos responsáveis e consciente de toda e qualquer escolha que fazemos na vida.

Ficar nessa de xingamentos nao levará ninguém a nada. A nada mesmo. Até pq somos todos iguais aos olhos de Deus.

Jovens, jesus nos ama e Deus tbm. Disso tenham certeza. Fiquem todos na paz.

Amém meus queridos.

Like - Reply - B 7 - June 27, 2015 at 12:13am

Galera, toda forma de amor é justa! Não precisam aceitar, é só respeitar as diferenças. Acho que todos deviam procurar a melhor maneira de ser feliz! 0 mundo precisa de mais amor. Quem dera se a sociedade fosse mais pacífica. . Talvez o mundo não estaria do jeito que está. . \#todaformadeamorévalido \#maisamor \#maisrespeito

Like - Reply - 10 - June 26.2015 at 10:00 pm
A É todo mundo querendo julgar todo mundo. Esquecendo que Deus nao deu autoridade para nemhum de nós julgarmos uns aos outros. O que foi deixado por jesus para nós aqui na terra foi a pratica do amor ao próximo. A palavra é bem clara! Amarás o senhor teu Deus sobre todas as coisas e ao teu próximo como a ti mesmo. "AMARÁS AO TEU PRÓXIMO COMO A TI MESMO" Em nemhum momento foi dito para julgar e condenar ao próximo. Ta tudo ao contrário. A palavra de Deus é amor e nao discórdia. Sei la... talvez vc nao goste que eu fale de Deus, mas qual argumento usaria diante de uma situação como essa? Eu nunca poderei querer ser um homem perfeito,porque sei que nao é possivel. Sou homem e estou em erro constante. Por isso Deus nos deixou a oportunidade de pedir perdao. Deus nunca cansa de perdoar a menos que o nosso arrependimento seja da boca pra fora. Resumindo; não serei eu que irá mudar o mundo, mas tambem não colaborarei para que ele piore.

Deus te abençoe meu querido.

Like - Reply - @1 - June 27,2015 at 8:44am

Fonte: Facebook

Desta forma, propõe-se, como forma de

representação dessas categorias, no intuito de visualizar as interseções entre elas, o diagrama de sentidos:

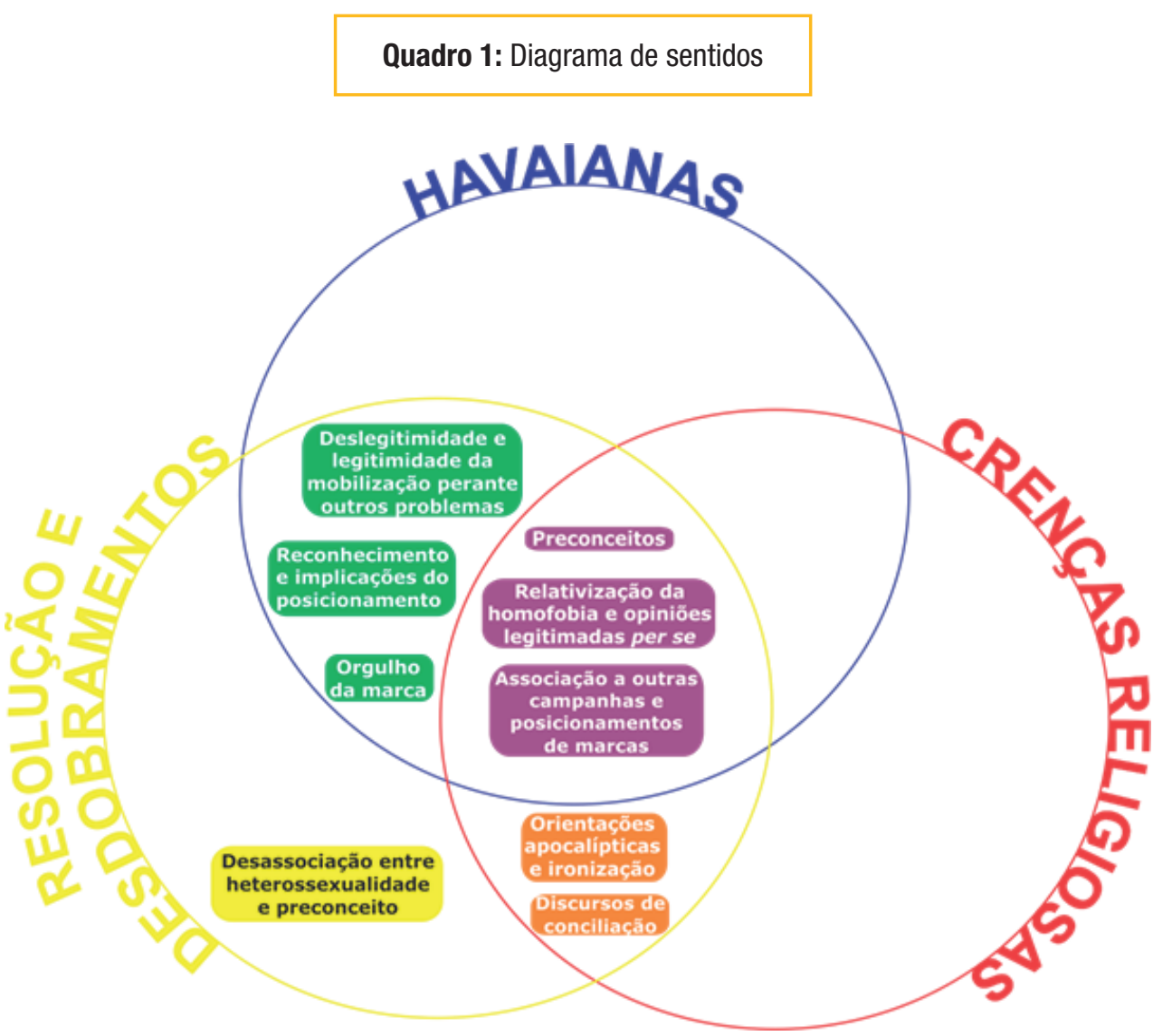




\section{Considerações finais}

Os modos como as apropriações da marca Havaianas, aqui analisadas, afetaram os atores sociais envolvidos nesse acontecimento/nessa conversação em rede (atores esses identificados como clientes e colaboradores) acentuam sentidos que ora aproximam esses atores, que endossam o posicionamento de celebração à decisão sobre 0 casamento igualitário, ora afastam os que expressam discursividade homofóbica (que prometem deixar de consumila). A ideia de pertencimento aparece fortemente constituída nessa paleta de sentidos (seja no orgulho de estar-se vinculado a uma marca que defende causas importantes, seja no aplauso que sugere fortalecimento de vínculos), assim como de ruptura (no caso das mensagens que condenam o posicionamento).

Esse acontecimento em rede coloca a marca na condição de protagonista de um debate numa sucessão de apropriações: da própria Havaianas em relação ao acontecimento em si (uma adesão no plano icônico, na textura visual da marca, à aprovação do casamento igualitário) e do modo como os atores vão se apropriando dessa apropriação ao gerar essa intensa conversação. Camadas de semioses vão se interpondo, atravessadas por sentidos conflitantes que têm, como fundo, a iconicidade gráfica da marca. Dessa forma, a marca coloca-se na condição de condutora de uma semiodiversidade e de uma narrativa espalhada, incorporando, com aparente eficácia estratégica, preceitos do ciberacontecimento. Em contrapartida, o debate em torno da homofobia ganha singular guarida nesse posicionamento.

Por outro lado, o exercício metodológico desenvolvido, designado como Análise de Construção de Sentidos em Redes Digitais, e expresso de forma visual no Quadro 1, pode identificar níveis de porosidades entre sentidos, como também nucleações que não geram interfaces. Defende-se que o desenvolvimento desta metodologia possa contribuir para identificar processos de constituição de territorialidades simbólicas nos processos que se articulam através dos sites de redes sociais.

\section{Referências}

ALSINA, M. R. La construcción de la noticia. Barcelona: Paidós, 1989.

AUSTIN, J. Quando dizer é fazer. Porto Alegre, Artes médicas, 1990.

BERGER, C.; TAVARES, F. Tipologias do acontecimento jornalístico. In: BENETTI, M; FONSECA, V. Jornalismo e Acontecimento: mapeamentos críticos. Florianópolis: Insular, 2010. BARDIN. L. Análise de conteúdo. Lisboa: Editora Edições 70, 1977.

BORILLO, D., Homofobia, história crítica de um preconceito. Belo Horizonte: Autêntica, 2010.

BUTLER, J. Problemas de gênero: feminismo e subversão da identidade. Editora Record, 2012.

CóRD0BA, D. Teoría queer: reflexiones sobre sexo, sexualidad e identidad. Hacia una politización 
de la sexualidad. In: CÓRDOBA, D.; SÁEZ, J.; VIDARTE, P. (Ed.). Teoría queer: políticas bolleras, maricas, trans, mestizas. Egales Editorial, 2005.

FRAGOSO, S.; RECUER0, R.; AMARAL, A. Métodos de pesquisa para internet. Porto Alegre: Sulina, 2011.

FONE, B. Homofobia, una historia. México: Editorial Océano, 2008.

HEINRICH, A. Networked Journalism. Londres: Routledge, 2011.

HENN, R. El ciberacontecimiento: producción y semiosis. Barcelona: Editorial UOC, 2014.

. Seis categorias para 0

ciberacontecimento. In: NAKAGAWA, Regiane Miranda; SILVA, Alexandre Rocha. (Org.). Semiótica da Comunicação II. São Paulo: Intercom, 2015,

HENN, R. C.; OLIVEIRA, F. M. Jornalismo e movimentos em rede: a emergência de uma crise sistêmica. Revista FAMECOS (Online). , v.22, p.1-19, 2015.

HENN, R.; MACHADO, F. V. K. Mas... e o beijo das travestis? De feliko e clarina, dos sentidos produzidos em rede e de quem pode (e como pode) beijar no horário nobre. Contemporânea (UFBA. Online). , v.13, p. 366-381, 2015.

HENN, R; GONZATTI, C. e MACHADO, F. V. K., JORDAN LIVES FOR THE APPLAUSE: performances de si como propulsoras de ciberacontecimentos. XXV Encontro Nacional da Compós. Goiânia, 2015. Acesso em: 02/07/2017. Disponível em: http://www.compos.org.br/ biblioteca.php.

YOUNG-BRUEHL, E. The anatomy of Prejudices. Cambridge: Harvard University Press, 1996.

JENKINS, H. Cultura da convergência. São Paulo: Aleph, 2009.
JENKINS, H.; FORD, S. e GREEN, J., Spreadable Media, Creatin, Value and Meaning in a Networked Culture. Nova York: New York University Press, 2013. LOTMAN, Y. Cultura y explosión, Lo previsible en los procesos de cambio social. Barcelona: Gedisa Editorial, 1999.

MACHADO, E; PALACIOS, M. (orgs). Modelos de jornalismo digital. Salvador: Calandra, 2003.

McCOMBS, M. A Teoria da Agenda. A mídia e a opinião pública. Petrópolis: Vozes, 2009.

MIELNICZUK, L. Jornalismo na web: uma contribuição para o estudo do formato da notícia na escrita hipertextual. 2003. Tese (Doutorado em Comunicação e Cultura) - Universidade Federal da Bahia, Faculdade de Comunicação, Salvador.

MISKOLCI, R. A Teoria Queer e a Questão das Diferenças: por uma analítica da normalização. In: CONGRESSO DE LEITURA DO BRASIL. 2007.

MISKOLCI, Ri. Teoria Queer: um aprendizado pelas diferenças. Autêntica, 2012.

PALÁCIOS, M. e NOCI, J. D. (Eds), Ciberperiodismo: métodos de investigación: Una aproximación multidisciplinar em perspectiva

comparada. Servicio Editorial de la Universidad del País Vasco, 2009.

PEIRCE, C. S., The Collected Papers of Charles Sanders Peirce. Past Masters, CD-ROM. EUA, InteLex Corporation, 2002.

PILZ, J. A ressignificação do ciberacontecimento pela publicidade: 0s sentidos oriundos da apropriação de \#meuamigosecreto pela Universal Pictures do Brasil no Facebook. In: XVII Congresso de Ciências da Comunicação na Região Sul, 2016, Curitiba. Anais do XVII Congresso de Ciências da Comunicação na Região Sul, 2016.

PRECIADO, B. Terror anal. El deseo homosexual. 2009 . 
PRIMO, A. Interação mediada por computador: comunicação, cibercultura, cognição. Porto Alegre:

Sulina, 2007

QUÉRÉ, Louis. Entre facto e sentido: a dualidade do acontecimento. Trajectos - Revista de Comunicação, Cultura e Educação. Lisboa, nº 6, 2005.

RECUERO, R. Warblogs: Os Weblogs, o Jornalismo Online e a Guerra no Iraque. Verso e Reverso (São Leopoldo), São Leopoldo, n.37. 2003.

A conversação em rede: Comunicação

Mediada Pelo Computador e Redes Sociais na Internet. Porto Alegre: Sulina, 2014.

RECUERO, R.; ZAG0, G. A Economia do Retweet: Redes, Difusão de Informações e Capital Social no Twitter. Contracampo, v. 1, p. 19-43, 2012

RUSSELL, A., Networked, a Contemporary History of News in Transition. Cambridge: Polity Press, 2011.

SCHWINGEL, C. Ciberjornalismo. São Paulo: Paulinas, 2012.

TRAQUINA, N. Teorias do Jornalismo. Porque as notícias são como são. V. 1. Florianópolis: Insular, 2004.

TUCHMAN, G. Making News: A study in the construction of reality. New York: The Free Press, 1983. 


\section{Equal Marriage celebration and} homophobia on the social network:

\section{\#LoveWins in the senses}

\section{dispute originated through}

\section{the Havaianas appropriation}

\section{Abstract}

The paper analyzes the senses originated in the process through the Brazilian flip-flop's brand Havaianas appropriates itself of the support manifestations in social network about the decision of the US Supreme Court, which legalized, in 2015, the equal marriage in that country. By updating its profile photo on Facebook using, in the first moment, the rainbow-colored filter and then by arranging flip-flops in the colors of the flag of the LGBT movement, the brand unleashed a conversation where the meanings of about the homophobia theme were built. The Havaianas action fits into the condition of Cyberevent and articulates intricate relationships that pass through gender issues, scattered narratives and permeability of media frontiers. The article also presents the methodological experience called the Sense Construction Analysis in Digital Networks, which deals with micro processes of the network conversation.

\section{Keywords}

Cyberevent. Dispute senses. Social networking sites.

\section{Celebración del matrimonio igualitario y homofobia en las redes digitales: \#LoveWins en la disputa de sentidos oriundos de la apropiación de la Havaianas}

\section{Resumen}

El trabajo analiza los sentidos oriundos del modo como Havaianas, la marca de sandalias brasileña, se apropia de las manifestaciones en red de apoyo a la decisión de la Corte Suprema de Estados Unidos, que hizo legal en 2015 el matrimonio igualitario en aquel país. Al actualizar su foto de perfil en Facebook con el filtro con los colores del arco iris y luego disponiendo las sandalias en colores que recuerdan la bandera del movimiento LGBT, la marca desencadenó una conversación en que sentidos alrededor del tema homofobia se establecerán. La acción de las Havaianas se enmarca en la condición de ciberacontecimiento y articula intrincadas relaciones que pasan por cuestiones de género, narrativas dispersas y permeabilidad de fronteras mediáticas. El artículo también presenta la experiencia metodológica designada como Análisis de Construcción de Sentidos en Redes Digitales, que se ocupa de procesos micros de la conversación en red.

\section{Palabras-clave}

Ciberacontecimiento. Sitios de redes socialies. Disputa de sentidos. 


\section{Expediente}

A revista E-Compós é a publicação científica em formato eletrônico da Associação Nacional dos Programas de Pós-Graduação em Comunicação (Compós). Lançada em 2004, tem como principal finalidade difundir a produção acadêmica de pesquisadores da área de Comunicação, inseridos em instituições do Brasil e do exterior.

\section{E-COMPÓS I www.e-compos.org.br I E-ISSN 1808-2599}

Revista da Associação Nacional dos Programas de Pós-Graduação em Comunicação.

Brasília, v.21, n.1, jan./abr. 2018.

A identificação das edições, a partir de 2008, passa a ser volume anual com três números.

Indexada por Latindex I www.latindex.unam.mx

\section{CONSELHO EDITORIAL}

Ada Cristina Machado Silveira, Universidade Federal de Santa Maria, Brasil Alda Cristina Silva da Costa, Universidade Federal do Pará, Brasil Alfredo Luiz Paes de Oliveira Suppia, Universidade Estadual de Campinas, Brasil Ana Regina Barros Rego Leal, Universidade Federal do Piauí, Brasil Ana Carolina Rocha Pessôa Temer, Universidade Federal de Goiás, Brasil André Luiz Martins Lemos, Universidade Federal da Bahia, Brasil Angela Cristina Salgueiro Marques, Universidade Federal de Minas Gerais, Brasil Ângela Freire Prysthon, Universidade Federal de Pernambuco, Brasil Antonio Carlos Hohlfeldt, Pontifícia Universidade Católica do Rio Grande do Sul, Brasil Arthur Ituassu, Pontifícia Universidade Católica do Rio de Janeiro, Brasil

Bruno Campanella, Universidade Federal Fluminense, Brasil

Cláudio Novaes Pinto Coelho, Faculdade Cásper Líbero, Brasil Cárlida Emerim, Universidade Federal de Santa Catarina, Brasil Carlos Eduardo Franciscato, Universidade Federal de Sergipe, Brasil Danilo Rothberg, Universidade Estadual Paulista, Brasil Denise Tavares da Silva, Universidade Federal Fluminense, Brasil Diógenes Lycarião, Universidade Federal do Ceará, Brasil Eduardo Vicente, Universidade de São Paulo, Brasil Eliza Bachega Casadei, Escola Superior de Propaganda e Marketing - SP, Brasil Eneus Trindade, Universidade de São Paulo, Brasil

Erick Felinto de Oliveira, Universidade do Estado do Rio de Janeiro, Brasil Erly Vieira Júnior, Universidade Federal do Espírito Santo, Brasil Francisco de Assis, FIAM-FAAM Centro Universitário, Brasi

Francisco Elinaldo Teixeira, Universidade Estadual de Campinas, Brasil Francisco Gilson R. Pôrto Jr., Universidade Federal do Tocantins, Brasil Frederico de Mello Brandão Tavares, Universidade Federal de Ouro Preto, Brasil Gabriela Reinaldo, Universidade Federal do Ceará, Brasil Gilson Vieira Monteiro, Universidade Federal do Amazonas, Brasil Gustavo Daudt Fischer, Universidade do Vale do Rio dos Sinos, Brasil Itania Maria Mota Gomes, Universidade Federal da Bahia, Brasil Jiani Adriana Bonin, Universidade do Vale do Rio dos Sinos, Brasil José Afonso da Silva Junior, Universidade Federal de Pernambuco, Brasil José Luiz Aidar Prado, Pontifícia Universidade Católica de São Paulo, Brasil Josette Maria Monzani, Universidade Federal de São Carlos, Brasi Juçara Gorski Brittes, Universidade Federal de Ouro Preto, Brasil
Juliana Freire Gutmann, Universidade Federal da Bahia, Brasil Laura Loguercio Cánepa, Universidade Anhembi Morumbi, Brasi Leonel Azevedo de Aguiar, Pontifícia Universidade Católica do Rio de Janeiro, Brasil Letícia Cantarela Matheus, Universidade do Estado do Rio de Janeiro, Brasil Luciana Coutinho Souza, Universidade de Sorocaba, Brasil Maria Ataide Malcher, Universidade Federal do Pará, Brasil Maria Elisabete Antonioli, Escola Superior de Propaganda e Marketing - SP, Brasil Maria das Graças Pinto Coelho, Universidade Federal do Rio Grande do Norte, Brasil Marialva Carlos Barbosa, Universidade Federal do Rio de Janeiro, Brasil Marcel Vieira Barreto Silva, Universidade Federal da Paraíba, Brasil Marcia Tondato, Escola Superior de Propaganda e Marketing, Brasil Marli Santos, Universidade Metodista de São Paulo, Brasil

Márcio Souza Gonçalves, Universidade do Estado do Rio de Janeiro, Brasil Mauricio Mario Monteiro, Universidade Anhembi Morumbi, Brasil Mayka Castellano, Universidade Federal Fluminense, Brasil

Mozahir Salomão Bruck, Pontifícia Universidade Católica de Minas Gerais, Brasil Nisia Martins Rosario, Universidade Federal do Rio Grande do Sul, Brasil Paolo Demuru, Universidade Paulista, Brasil

Paula Melani Rocha, Universidade Estadual de Ponta Grossa, Brasil Potiguara Mendes Silveira Jr, Universidade Federal de Juiz de Fora, Brasil Priscila Ferreira Perazzo, Universidade Municipal de São Caetano do Sul, Brasil Rafael Cardoso Sampaio, Universidade Federal do Paraná, Brasil Rafael Tassi Teixeira, Universidade Tuiuti do Paraná, Brasil Regiane Lucas Garcês, Universidade Federal de Minas Gerais, Brasil Regiane Regina Ribeiro, Universidade Federal do Paraná, Brasil Renata Pitombo Cidreira, Universidade Federal do Recôncavo da Bahia, Brasil Renato Essenfelder, Escola Superior de Propaganda e Marketing, Brasil Roberto Elísio dos Santos, Universidade Municipal de São Caetano do Sul, Brasil Rodolfo Rorato Londero, Universidade Estadual de Londrina, Brasil Roseli Figaro, Universidade de São Paulo, Brasil

Simone Maria Andrade Pereira de Sá, Universidade Federal Fluminense, Brasil Sofia Cavalcanti Zanforlin, Universidade Católica de Brasília, Brasil Sônia Caldas Pessoa, Universidade Federal de Minas Gerais, Brasil Tatiana Oliveira Siciliano, Pontifícia Universidade Católica do Rio de Janeiro, Brasil Thaïs de Mendonça Jorge, Universidade de Brasília, Brasil

Valquiria Michela John, Universidade Federal do Paraná, Brasil

\section{CONSELHO CIENTÍFICO}

Cristiane Freitas Gutfreind, Pontifícia Universidade Católica do Rio Grande do Sul, Brasil I Eduardo Antônio de Jesus, Universidade Federal de Minhas Gerais, Brasil | Eduardo Morettin, Universidade de São Paulo, Brasil I Irene de Araújo Machado, Universidade de São Paulo, Brasil I Miriam de Souza Rossini, Universidade Federal do Rio Grande do Sul, Brasil

\section{COMISSÃO EDITORIAL}

Igor Pinto Sacramento, Universidade Federal do Rio de Janeiro, Brasil I Kelly Cristina de Souza Prudencio, Universidade Federal do Paraná, Brasil I Osmar Gonçalves dos Reis Filho, Universidade Federal do Ceará, Brasil I Rafael Grohmann, Faculdade Cásper Líbero, Brasil I Thaiane Moreira de Oliveira, Universidade Federal Fluminense, Brasil (editores associados)

\section{CONSULTORES AD HOC}

Afonso de Albuquerque, Universidade Federal Fluminense, Brasil I Cláudia Lago, Universidade de São Paulo, Brasil I Cesar Baio Santos, Universidade Federal do Ceará, Brasil I Eduardo Pellanda, Pontifícia Universidade Católica do Rio Grande do Sul, Bras | Francisco Rüdiger, Pontifícia Universidade Católica do Rio Grande do Sul, Brasil | Karina Woitowicz, Universidade Estadual de Ponta Grossa, Brasil I Luis Mauro Sa Martino, Faculdade Cásper Líbero, Brasil I Norval Baitello Jr, Pontifícia Universidade Católica de São Paulo, Brasil I Pedro Guimarães, Universidade de Campinas, Brasil

\section{EQUIPE TÉCNICA}

ASSISTENTES EDITORIAIS Márcio Zanetti Negrini e Melina Santos | REVISÃO DE TEXTOS Fátima Áli I EDITORAÇÃO ELETRÔNICA Roka Estúdio

COMPÓS I www.compos.org.br

Associação Nacional dos Programas de Pós-Graduação em Comunicação

Presidente

Marco Roxo

Programa de Pós-Graduação em Comunicação - UFF

marcos-roxo@uol.com.br

Vice-Presidente

Isaltina Gomes

Programa de Pós-Graduação em Comunicação - UFPE

isaltina@gmail.com

Secretária-Geral

Gisela Castro

Programa de Pós-Graduação em Comunicação

e Práticas de Consumo - ESPM

castro.gisela@gmail.com

CONTATO I revistaecompos@gmail.com 